\title{
DIFFUSION, OSMOTIC PRESSURE, AND IMBIBITION IN HIGH SCHOOL BIOLOGY.
}

By Aleita Hopping,

DeWitt Clinton High School, New York City.

(Continued from May.)

Osmotic Pressure and Gas Pressure.

As is well known, van't Hoff, a physicist, using Pfeffer's direct determinations of osmotic pressure, arrived at the equation $\mathrm{P}=n \mathrm{RT} / v$, where $\mathrm{P}$ is the osmotic pressure, $\mathrm{T}$ the absolute temperature, $R$ a constant, $n$ the number of gram molecules of solute in volume $v$. This is the well known equation for gases. The equation holds exactly only for dilute solutions. Osmotic pressure, then, may be regarded as equal to the pressure the solute would exert, as a gas, occupying the volume of the solution or of the solvent. Since gas pressure is considered to be due to the kinetic energy of moving particles, it follows that a similar explanation may be offered for osmotic pressure, namely, that the pressure is exerted by the solute particles in the solution.

Many determinations of the osmotic pressure of substances in solution have been made, and it has been found that the calculated values, using the gas pressure formula, do not agree with the observed values, in case of concentrated solutions. For this reason, the simple form of the gas pressure theory has has been modified to meet these conditions, but the validity of the theory has not, of course, been altered. Substances in solution undergo a chemical union with water (or solvent), producing stable hydrates, and thus reducing the volume of the solvent. Cane sugar forms a hydrate with water and is represented by the formula $\mathrm{C}_{12} \mathrm{H}_{22} \mathrm{O}_{11} \cdot 6 \mathrm{H}_{2} \mathrm{O}$; the volume occupied by the solute must therefore be considered as the volume of the unassociated solvent, not as the volume of the solution.

The rapidity of movement of sugar molecules through a membrane is probably influenced by the attractive forces that exist between the molecules of sugar and of water. When a substance is dissolved in water, ordinarily the surface tension of the water is lowered. When a solution and solvent are separated by a membrane, permeable to the solvent, the higher surface tension of the solvent would cause a movement through the membrane into the solution.

\section{IMBIBITION.}

The colloids, like glue, gelatine, albumin, gum arabic, etc., all absorb water to a marked extent. Silicie acid in the colloidal 
state has a solid form and yet consists of 90 per cent. of water. Colloids absorb water and swell, and this process is called imbibition. There is usually a limit to the amount of swelling, though in many substances the form of the swelling body merely ehanges from the solid to the liquid condition. In experiments with Laminaria, a seaweed, which behaves like a colloid, parts of this plant absorbed water and swelled 300 per cent., by volume under one atmosphere pressure, and even under forty-one atmospheres, it increased 16 per cent. of its volume, thus expanding under a pressure of 615 pounds per square inch. This process is accompanied by liberation of heat, which is called heat of imbibition. When one gram of dry gelatine swells, 5.7 calories of heat are given out. In case of gum arabic this is equal to 9.0 calories..$^{1.8}$

In imbibition the absorption of water may be due to capillary forces, acting in very small spaces; as is well known, some substances wet one another, like water and glass, while other substances, like mercury and glass, do not: In cases where substances do wet one another the forces of adhesion, the tendency of unlike substances to stay together, comes into play. The molecules of water are attracted by the glass, and in the case of capillary tubes, water rises in the tube. When substances imbibe water, it is understood that the water molecules are absorbed in and become regularly scattered about the molecules of the substance, the two masses remaining in the solid condition. The amount of water held in this way has a limit; if this limit is exceeded as by raising of the temperature, the mass passes into a liquid condition. Thus gelatine will absorb water and remain a stiff jelly; if this is heated it becomes a liquid.

It will be remembered that the osmotic pressure of crystalloids is proportional to the concentration and the temperature. When mixtures are studied, the effect is found to be purely additive, the osmotic pressure of the second substance is added to that of the first. The osmotic pressure of colloids is, of course, very low, and is very unstable. There is no definite relation between the osmotic pressure and temperature or concentration. The influence of added substances is various. Acids and alkalies, even in very dilute solution, markedly increase the osmotic pressure, whereas salts always decrease it. Thus a 1.25 per cent solution of albumin gave an osmotic pressure of $21.6 \mathrm{~mm}$. of a mercury column, but when a trace of copper chloride was ${ }^{18}$ Hatschek, Emil, An Introduction to the Physics and Chemistry of Colloids, Philadelphia,
1916, pages 59-60. 
added this value fell to $1.6 \mathrm{~mm}$. It is true also that substances that decrease osmotic pressure of colloids also decrease their swelling and the action is almost identical. ${ }^{19}$ From these facts, as well as others, it is suggested that the structure of the material undergoing swelling acts as a selectively permeable membrane, and that osmosis of colloid solutions might well be termed a swelling of liquids in contrast to the usual swelling of solids.

\section{Diffusion and Osmotic Pressure in Brology.}

Diffusion plays a very important role in biology. In cases where there are no mass movements of materials, these movements are in general due to diffusion. In plants, particularly, diffusion plays a very important part. Here mass movements of liquids within the plant are confined mostly to the movement of water, in the transpiration stream, and in protoplasmic streaming. Convection currents are probably active to some extent. The entrance of oxygen and carbon dioxide into leaves probably occurs mostly by gas diffusion. If the cell walls lining the air spaces are moist the gases probably dissolve and then pass into the cells by solution diffusion, which we have seen is in no essential way different from gas diffusion. Stomata in the leaves, and the lenticels in the bark, allow gases to enter into and pass out of the leaves and the stem, and thus to reach the cells by diffusion. The gases are dissolved there, in the liquid parts of the cells. Mineral matter dissolved in the soil water may pass by diffusion into the cells, though it is more probable that it is moved along with soil water in the transpiration stream, or absorbed by the colloids of the cell contents.

In animals, diffusion plays an important role. According to Fischer ${ }^{20}$; the absorption of foods from the lumen of the food tube is in large part due to diffusion. The food in the mouth, stomach, and intestine is partially digested, the colloidal substances, like starch, fat, and protein, which cannot diffuse through membranes, being changed into the crystalloids, sugar, fatty acids, and glycerine, and peptone. Fat when emulsified is able to pass through the intestinal membranes, though it is still in the colloidal condition. The membranes of the intestine are quite permeable to sugar, peptone, glycerine, and fatty acids, and seem to offer little or no resistance to diffusion. These ${ }^{19}$ Ostwald, Wolfgang, Handbook of Colloid Chemistry, tranglated from the whird German pdition by Martin H. Fischer, 1915.

20 Fischer, Martin, Physiology of Alimentation, New York, 1907. 
substances are all in great quantity in the food tube, and rapidly diffuse out as a result. The membranes, of course, must be regarded as consisting not merely of the outer layer of protoplasm in the individual cells, but may be regarded as a whole series of cells acting together. The digested foods pass by diffusion. through the walls of the villi and pass into the blood and lymph, and eventually are earried by mass movements of the blood to all parts of the body.

In the tissues, the process of diffusion occurs again, the food passing from the blood, where it is in a concentrated condition, into lymph, and then into the protoplasm, where it is oxidized and changed into carbon dioxide, urea, etc. The carbon dioxide and urea diffuse out of the cells, into the lymph or capillaries, and then are carried by mass movements to the lungs. In the tissues, the nutrients from the plasma pass into the lymph through the membranes of the capillaries and into the protoplasm. In the lungs, the carbon dioxide by solution diffusion passes into films of mucus and water lining the air sacs, and then by gas diffusion into the air spaces. By mass movements due to contraction of the chest cavity, it is expelled out of the body, into the surrounding air. The excretion of urea cannot be thus easily explained, for in the kidneys, urea leaves the blood, where there is relatively, little of it, and passes into the kidneys, where there is an accumulation of it, and is thus seen to be not a movement of diffusion. The secretion of materials by colloidal substances will probably be called upon to explain this process.

The role of somotic pressure in plants and animals is still much discussed. The osmotic value of the blood is almost as constant as the body temperature. In different animals the osmotic value of the blood is very different. When liquids are injected into the circulatory system after loss of blood, the solutions used are so made as to have an osmotic value, corresponding to that of the blood.

Turgidity of cells may be due to imbibition, attraction of cell colloids for water, or to osmotic pressure. It has been explained how colloids absorb water and swell, developing great pressures. The swelling pressure of imbibition is very important in explaining the pressures developed during the growth of roots and delicate plant parts.

When a plant cell is surrounded by a solution of greater concentration than that contained within its vacuole, the phenomenon of plasmolysis occurs. The greater osmotic pressure of the 
solutes outside, together with the slight resilience of the protoplasm, causes a contraction of the protoplasm, which separates from the enclosing cellulose wall. If the process of plasmolysis is complete, the vacuole may disappear, practically all the water passing out. In such cases, the protoplasm takes the form of a sphere, lying at the middle or side of the cell. Plasmolysis usually occurs within a very few minutes after the cell has been immersed in the solution. When a solution of known concentration just causes plasmolysis, it follows that the osmotic value of the cell sap must then be equal to that of the solution surrounding the cell. Here is a way to find the concentration of the cell sap.

When an organ of a plant is placed in a solution, the osmotic value of which is less than that of the cell contents, and to which the cell membrane is impermeable, or slowly permeable, water passes from outside through the membranes into the cells of the organ, and the organ is swollen or turgid. If the outer solution is replaced by a solution having a higher osmotic value than the cell contents, water passes out of the cells into the solution and the organ is wilted or plasmolysed. Under natural conditions, the organs of the plant body are surrounded by liquids, the osmotic pressure of which is lower than that of the cell contents, so they are usually turgid, or they are surrounded by gases. Of course, when water is removed by any other means, as by evaporation, the leaves or cells also wilt, and lose their turgor.

To some substances protoplasm is quite impermeable, to the majority of substances it is very slightly permeable, and to some substances it is usually very readily permeable. Cane sugar, glucose, and $\mathrm{NaCl}$ ordinarily penetrate cells to some extent, though slowly. Glycerine and urea penetrate with great readiness. Ethyl alcohol, acetone, caffein, formaldehyde, penetrate cells so rapidly that no plasmolysis occurs.

Both imbibition and osmotic pressure are important in the retention of form of plants and animals, in mechanical support, growth, and in the performance of work by growing parts.

Changes in the osmotic value of a solution may change the extent to which water is absorbed, increasing or decreasing absorption. Changes in the water-attracting power of colloids may also have the same effect. Colloids are altered by presence of slight traces of salts, acids, etc. Great quantities of water are absorbed daily from the alimentary tract, four or five liters in the course of a day, in some cases. Some of this absorption 
is due to differences in osmotic pressure, but probably much more is due to the enormous affinity of colloids for water. Protoplasm is, of course, a mixture of many substances in the colloidal condition, and as is well known consists of about 80-90 per cent. of water.

Absorption of water by roots is probably due as much to imbibition of water by colloids as to diffusion or "osmosis."

\section{CONCLUSION.}

Since osmosis is the diffusion of substances through membranes, the word is unnecessary, and confusing, and ought to be dropped. The direction of osmotic movements should not be described as being from the "less to the more dense." Diffusion of substances in solution, and diffusion of gases, ought to be taught as thoroughly as possible, the laws governing it, and the causes underlying it, that is, the intrinsic or kinetic energy of molecules.

Most movements of materials in the body when the substances are in the molecular conditions are due to diffusion. The absorption of water by colloids, imbibition, should be studied. Osmotic pressure should be explained upon the basis of the diffusion of dissolved substances and should be shown to be due to the kinetic energy of the molecules. Osmotic pressure and imbibition should be studied only in advanced classes. Diffusion should be studied in elementary and advaneed classes.

The role of osmotic pressure, imbibition, and diffusion in plants and animals should be taken up, the importance in retention of form of cells, and delicate parts, turgidity of cells, and organs, etc. The diffusion of substances such as foods and gases should also be studied.

\section{OUTLINE.}

NOTE: Single star $\left({ }^{*}\right)$ denotes topics for elementary work, double star $\left(^{* *}\right)$ indicates subjects to be taken up in advanced work.

Theory of Diffusion, Osmotic Pressure, Imbibition.

*A.

I. Diffosion.

(a.) Diffusion of substances in the air

(1). Steam in a room

(2). Perfume of flowers

(3). Cigar smoke

(4). Mustard gas

(b). Diffusion of substances dissolved in water

(1). Ink in water

(2). Copper sulphate in water

(3). Sugar in water 
(c). Direction of diffusion

Substances diffuse from regions of higher to those of lower concentration

(d). Diffusion through a membrane

(1). Thistle tube, parchment paper, filled with starch

(2). Same, filled with sugar

(3). Sugar diffuses through membrane, starch does not

**II. Osmotic Pressure

(a). Sugar in thistle tube, parehment paper

(1). Note rise of liquid in tube

(2). Test for sugar

(3). Note rapid passage of $\mathrm{H}_{2} \mathrm{O}$ through membrane and slower passage of sugar

(b). Direction of flow

(1). Solvent flows into solution through semipermeable membrane into solute, and a hydrostatic pressure is developed which is a measure of the osmotic pressure

(c) Explanation

(1) $\mathrm{H}_{2} \mathrm{O}$ diffuses from where there is much of it to where there is little of it

(2) Sugar diffuses out if membrane is permeable

(3) Sugar may attract water and cause absorption

**III. IMBIBITION

(a) Experiment

Glue or gelatine or egg albumin separated from water by a parchment paper membrane

(b) Direction of flow

Water is absorbed by the colloid, which cannot pass through the membrane

(c) Explanation

Glue and egg albumin are colloids and absorb water (imbibition), this due to attraction between the molecules, or may also be due to diffusion of the water molecules

B. Impontance of Diffusion, Osmotic Pressure and Imbibition *I. Diffusion

1. In plants

(a) Absorption of mineral matter

Here membrane is permeable to salts and to water, water and mineral matter moves from denser to more dilute (outer solution of soil, into cell sap)

(b) In leaves

Gaseous exchange:

In night-

(1) Much $\mathrm{O}$ in air, little in leaves, $\mathrm{O}$ diffuses in

(2) Much $\mathrm{CO}_{2}$ in leaves, little in air, $\mathrm{CO}_{2}$ diffuses out

In day-

(3) Much $\mathrm{O}$ in leaves, much in air, may stay in or go out, depending on the rate of photosynthesis

(4) Much $\mathrm{CO}_{2}$ in leaves, some in air, but $\mathrm{CO}_{2}$ is used up faster than produced, so some moves in from air

2. In animais

(a) Passage of food in small intestine into blood and villi, and from blood into cells

(1) Membranes of blood vessels and of villi are permeable to peptone, sugar, emulsion of fat. Impermeable to proteid, starch, fat. Dissolved peptone, sugar, and emulsified fat, concentrated in small intestine, diffuse into lymph and blood, where there is little of these substances

(2) Passage of food from blood into lymph spaces and into cells

More of dissolved food in blood, in eapillaries, less in lymph 
and cells, so passage of these substances by diffusion from blood into lymph and then into cells

(b) Exchange of $\mathrm{O}$ and $\mathrm{CO}_{2}$ in lungs and tissues

(1) In lungs

(a) Membranes permeable to both $\mathrm{CO}_{2}$ and $\mathrm{O}$

(b) Much $\mathrm{CO}_{2}$ in blood, little in air; $\mathrm{CO}_{2}$ passes from blood into air

(c) Much $\mathrm{O}$ in air, little in blood, $\mathrm{O}$ passes into blood from air

(2) In tissues

(a) Membranes permeable to each

(b) Much $O$ in blood, little in cells, $O$ passes from blood into cells

(c) Mueh $\mathrm{CO}_{2}$ in cells, less in blood, $\mathrm{CO}_{2}$ passes from lymph and eells into blood

(c) Gaseous exchange in fish

(1) Membranes of gill fringe and of capillaries permeable

(2) Much dissolved $\mathrm{O}$ in water, little $\mathrm{CO}_{2}$

(3) $\mathrm{O}$ diffuses into blood, $\mathrm{CO}_{2}$ diffuses out

**II. Osmotic Pressure

1. In plants

(a) Absorption of water by roots may cause rise of water in stem; this due to imbibition also

(b) Plasmolysis and turgidity

(1) Place leaves in strong sugar solution, they wilt, water passes from leaves into sugar solution

(2) Place these leaves in water, they revive; water passes into leaves

(3) Pressure resulting in turgidity due to diffusion pressure of solute which cannot pass through semipermeable membranes, or to attraction of solute for water

(4) Importance of turgidity and osmotic pressure in retention of form and shape of plants

2. In animals

(a) Plasmolysis and turgidity

(See Osmotic Pressure in plants)

(b) Osmotic pressure of blood is almost as constant as body temperature, different in different animals

(c) Importance of osmotic pressure in injection of solutions into blood

**III. IMBIBITION

1. In plants

Absorption of water by protoplasm

Energy of growth

2. In a nimals

Absorption of water by protoplasm

Energy of growth

\section{BOYS' AND GIRLS' CLUB MOVEMENT.}

The educational value of the boys' and girls' elub movement is none the less because of the emphasis that the clubs place upon productive work and the earning of money. Against "ehild labor" there was been a merited protest, for child labor is the deliberate premature exploitation of the Nation's most precious resources. But to exclude boys and girls from all participation in productive work would be to deprive them of the kind of experience that will best fit them to "pull their own weight" when the time comes for them to take the oars. The problem is not to keep ohildren away from work, but rather to induct them in to it gradually and with an eye single to its educational influence. The boys' and girls' clubs, like the School Garden Army, represent an organized and intelligent effort to solve this problem.-[School Service. 